\title{
Persistence of Anti-Hbs after up to 30 Years in Health Care Workers Vaccinated against Hepatitis B Virus
}

\author{
Silvia Cocchio ${ }^{1}$, Vincenzo Baldo ${ }^{1, *(\mathbb{D})}$, Anna Volpin ${ }^{1}$, Marco Fonzo ${ }^{1}\left(\mathbb{D}\right.$, Annarosa Floreani ${ }^{2,3}$, Patrizia Furlan ${ }^{1}$, \\ Paola Mason ${ }^{1}$, Andrea Trevisan ${ }^{1}\left[\right.$ and Maria Luisa Scapellato ${ }^{1}$ \\ 1 Department of Cardiac Thoracic and Vascular Sciences, and Public Health, University of Padua, \\ 35100 Padova, Italy; silvia.cocchio@unipd.it (S.C.); anna.volpin@aopd.veneto.it (A.V.); \\ marco.fonzo@unipd.it (M.F.); patrizia.furlan@unipd.it (P.F.); paola.mason.1@unipd.it (P.M.); \\ andrea.trevisan@unipd.it (A.T.); marialuisa.scapellato@unipd.it (M.L.S.) \\ 2 Scientific Institute for Research, Hospitalization and Healthcare Negrar, 37024 Negrar, Italy; \\ annarosa.floreani@unipd.it \\ 3 Department of Surgical, Oncological and Gastroenterological Sciences, University of Padua, \\ 35124 Padova, Italy \\ * Correspondence: vincenzo.baldo@unipd.it
}

\section{check for} updates

Citation: Cocchio, S.; Baldo, V.; Volpin, A.; Fonzo, M.; Floreani, A.; Furlan, P.; Mason, P.; Trevisan, A.; Scapellato, M.L. Persistence of Anti-Hbs after up to 30 Years in Health Care Workers Vaccinated against Hepatitis B Virus. Vaccines 2021, 9, 323. https://doi.org/ $10.3390 /$ vaccines 9040323

Academic Editors: Artur Summerield and Magdalena A. Berkowska

Received: 18 February 2021

Accepted: 24 March 2021

Published: 1 April 2021

Publisher's Note: MDPI stays neutral with regard to jurisdictional claims in published maps and institutional affiliations.

Copyright: (c) 2021 by the authors. Licensee MDPI, Basel, Switzerland. This article is an open access article distributed under the terms and conditions of the Creative Commons Attribution (CC BY) license (https:/ / creativecommons.org/licenses/by/ $4.0 /)$.
Abstract: The burden of hepatitis B virus (HBV) infection is a serious public health problem all over the world. Vaccination remains the most effective prevention measure, and safe and effective HBV vaccines have been available since 1982. Health care workers (HCWs) vaccinated against HBV and prospectively followed up for at least 14 years were classified by their antibody titers after primary vaccination as: poor responders (10-99 $\mathrm{mIU} / \mathrm{mL})$; moderate responders (100-999 $\mathrm{mIU} / \mathrm{mL})$; and good responders $(\geq 1000 \mathrm{mIU} / \mathrm{mL})$. The incidence of antibody loss was calculated for 1000 personyears and the anti-HBs persistence was calculated. The analysis concerned 539 HCWs: 494 good responders (91.7\%); 37 moderate responders (6.9\%); and eight poor responders $(1.5 \%)$. The incidence of anti-HBs loss was 52.1 per 1000 person-years for the poor responders, 11.3 per 1000 person-years for the moderate responders, and 1.4 per 1000 person-years for the good responders. The mean persistence of anti-HBs differed significantly between the three groups, being: 19.2 years (95\% CI: 15.6-22.8), 25.4 years (95\% CI: 23.0-27.9), and 31.0 years (95\% CI: 30.5-31.5) for the poor, moderate and good responders, respectively. In conclusion, our findings demonstrate a good persistence of protective anti-HBs titers in HCWs exposed to occupational risk for up to 30 years after a primary vaccination cycle (even without a booster dose) if their titer was initially higher than $100 \mathrm{mIU} / \mathrm{mL}$.

Keywords: HBV; vaccination; anti-HBs; health care workers

\section{Introduction}

Hepatitis B virus (HBV) infection remains a public health problem all over the world. Around 250 million people live with chronic HBV infection [1,2] and roughly $30 \%$ of the world's population would show serological evidence of current or past infection [3]. Most acute infections are asymptomatic. Over the years after contracting the virus, approximately $15-40 \%$ of chronically-infected patients gradually develop serious HBV-related symptoms. These symptoms of their hepatitis may involve cirrhosis, liver failure, and hepatocellular carcinoma, and nearly a million people around the world die every year due to the complications of HB-related disease [4].

Although HBV infection is a globally relevant concern, not all regions in the world are equally affected and the prevalence of hepatitis due to the HBV shows significant variations across countries: the prevalence is the lowest in Northern America and Western Europe, where less than $2 \%$ of the general population is estimated to be positive to the $\mathrm{HBaAg}$; it ranges between $2 \%$ and $8 \%$ in the Mediterranean Region, Eastern Europe, and most Asian countries; it stands above $8 \%$ in some low income (LIC) and low and middle-income countries (LMIC) in Asia and Sub-Saharan African countries [5]. 
In 2017, 30 EU/EEA Member States reported 26,907 cases of HBV infection. Excluding the five countries that only reported acute cases, the number of cases identified $(26,262)$ amounts to a crude rate of 6.7 per 100,000 population. The number of acute cases seen in Europe continues to decline, consistently with global trends, and most likely reflects the impact of national vaccination programs [6]. In this regard, Italy is not an exception, and the epidemiology of HBV infection showed a noteworthy change during the last five decades. A substantial and progressive reduction has been seen in both the incidence of acute hepatitis B cases (dropping from 10 cases per 100,000 population in 1984 to less than 1 case- 0.85 , to be precise-per 100,000 population in 2012) and the prevalence of HBsAg chronic carriers (moving from 3\% in the early 1980s to less than 1\% in 2010). The reasons for this achievement are health-related but also social: an improvement in the socioeconomic level of the general population; a reduction in the number of large families in which HBV transmission often occurs between siblings; the effects of educational campaigns aimed primarily at containing the spread of the HIV infection; the availability of HBV screening test for pregnant women and, last but not least, the implementation of a nationwide universal vaccination program [5].

Compared with the general population, healthcare workers (HCWs) are at higher risk for transmission of a wide range of blood-borne infectious agents, including-by way of example but not limited to- the hepatitis B virus (HBV), the hepatitis C virus (HCV) and the human immunodeficiency virus (HIV). Of the above pathogens, the HBV is far more infectious than both HCV and, even to a greater extent, HIV [7]. HCWs are more exposed to the risk of acquiring HBV infection than members of the general population due to the frequent exposure of their eyes, oral mucosa, and skin to patients' potentially infectious blood. They may also contract the disease percutaneously from contaminated sharp objects (needles, blades, etc.) [8,9]. The annual estimated proportion of HCWs exposed to HBV is $5.9 \%$, which corresponds to an estimated 66,000 preventable HBV infections each year among HCWs worldwide [10].

The adoption of numerous different measures and interventions, and the use of standard precautions and safety devices have helped to reduce the risk of HBV transmission, but the development of vaccines against HBV has undeniably been one of the most important achievements in terms of the prevention of HBV infection [7].

HCWs represent one of the most important groups to protect against HBV infection in adults [11,12]. Safe and effective HBV vaccines have been commercially available since 1982. After the first plasma-derived vaccines, recombinant DNA vaccines were licensed. Yeast-product vaccines (the most widely used) are manufactured by inducing the expression of HBsAg protein in genetically-engineered yeast cells that contain the $S$ gene. The protective efficacy of HBV vaccination stems from the induction of anti-HBs antibodies at concentrations above $10 \mathrm{mIU} / \mathrm{mL}$ [13]. It has been demonstrated that these vaccines are safe when administered to infants, children, adolescents, and adults. The side-effects most frequently reported in people receiving hepatitis $\mathrm{B}$ vaccine are pain at the injection site (in $3 \%$ to $29 \%$ of cases) and a transient mild fever $>99.9{ }^{\circ} \mathrm{F}\left(>37.7^{\circ} \mathrm{C}\right.$ ) (in $1 \%$ to $6 \%$ of individuals) [14].

Studies indicate that immunological memory of HBV remains intact for at least 30 years $[15,16]$. Immunocompetent individuals who achieve hepatitis B surface antibody (anti-HBs) concentrations of $\geq 10 \mathrm{mIU} / \mathrm{mL}$ after being vaccinated prior to any exposure to the virus are protected against both acute disease and chronic infection [17]. This remains true even if their anti-HBs levels, once measured and found adequate, subsequently drop even to below detectable levels. If exposed to HBV, people whose immune systems are competent will mount an anamnestic response and develop protective anti-HBs [16]. Smoking, obesity, genetic factors, male gender, pre-existing rheumatic disease, and immune suppression are associated with a diminished immune response to hepatitis B vaccination, although not all evidence is unanimous regarding the factors listed above [18-20]. The effect of obesity or obesity-related diseases on HBV vaccine-escape mutation remains unclear, but the impaired vaccine response in obesity still poses a challenge in reaching 
effective immunization against HBV [21]. In addition, although immunocompromised individuals have lower immunogenicity, those who achieve and maintain a protective antibody response before exposure to HBV nonetheless have a high level of protection against infection [22].

It has generally been reported that an individual's antibody titers decline over the years after their immunization. This coincides with a gradually increasing rate of infection, especially when the titer of the antibody against hepatitis B surface antigen (HBsAg) falls below the protective cut-off level of $10 \mathrm{mIU} / \mathrm{mL}$ [23]. However, variation in policies on booster dose administration for HCWs in Europe and the USA has been reported, with wide differences between no recommendation for adults whose immune status is normal in the USA, and recommendation for booster dose within one year in case of anti-HBs titer $<100$ mIU in Germany. A recent statement from the Consensus Committee Group of Experts does not recommend a booster dose for HCWs but recommends immunization for any health care workers for whom a vaccination record cannot be traced. Moreover, they recommend post-vaccination antibody testing and administration of an additional dose of vaccine in cases of inadequate immunological priming [24]. Studies are ongoing to ascertain whether booster doses of hepatitis B vaccine will be needed in the future [16].

We started a vaccination campaign for groups at risk of HBV in 1983. We subsequently studied the persistence of seroprotection induced by HBV vaccination in $422 \mathrm{HCWs}$ from 4.8 to 18.8 years after their primary immunization, and 107 of these HCWs had received a booster dose 6 years after primary immunization with plasma- or yeast-derived vaccines [25]. In the cohort not given a booster dose, it emerged that the cumulative proportion of HCWs still protected against HBV after 10 years was $>85 \%$. The study thus concluded that a booster dose is not necessary for healthy adults, since more than $80 \%$ of responders to vaccination still had protective antibody titers detectable after 10 years, and bearing in mind that immunological memory persists for more than 10 years. Our prospective study on the effects of offering vaccination to HCWs has continued over time and, within this context, we have also looked at the cohort of individuals not given a booster dose. Following them up to assess the persistence of anti-HBs can be useful for the purpose of public health considerations on the best immunization strategies for HCWs.

\section{Material and Methods}

\subsection{Context}

Our vaccination campaign started in January 1983 for all individuals belonging to groups at high risk of becoming infected with the HBV virus. HCWs found negative for HBV markers (HBsAg, anti-HBs, and anti-HBc) were offered vaccination against $\mathrm{HBV}$ with:

(1) plasma-derived vaccines (HEVAC-B (Pasteur, Merieux, Lyon, France) at 0, 1, 2, and 14 months or HB-Vax (Merck Sharp and Dohme, Sumneytown Pike, Westpoint, PA, USA) at 0, 1, and 6 months), up until the end of 1989;

(2) yeast-derived vaccines (Engerix-B (Smith Kline Beecham Biological, Rixensart, Belgium) and Recombivax (Merck Sharp and Dohme)) at 0, 1, and 6 months, as of 1990.

\subsection{Study Population}

HCWs vaccinated during the campaign against HBV were prospectively followed up for at least 14 years. Their anti-HBs antibody titers were measured at the end of the primary immunization cycle, and then at various different times afterward, as part of the HCWs' preventive medical check-ups according to the Occupational Health Protocol. The anti-HBs antibody titers of the end of the primary vaccination cycle and as at the latest available measurement (no later than February 2019) were considered in our study on a cohort of HCWs not given a booster dose.

\subsection{Laboratory Methods}

HBV markers (HBsAg, anti-HBs, and anti-HBc) were tested, always at the same laboratory, by radioimmunoassay (AUSIA II, AUSAB, and CORAB B, Abbott Labs, Chicago, IL, 
USA) according to the manufacturer's recommendations. As generally accepted, vaccinated subjects were considered as seroprotected when their anti-HBs titers were $\geq 10 \mathrm{mIU} / \mathrm{mL}$. After primary vaccination, the HCWs were classified by antibody titer as: (i) poor responders (10-99 mIU/mL); (ii) moderate responders (100-999 mIU/mL); and (iii) good responders $(\geq 1000 \mathrm{mIU} / \mathrm{mL}$ ). Antibody loss and antibody persistence were defined as testing negative or positive for anti-HBs, respectively, according to the results of the commercial kits.

\subsection{Statistical Analysis}

The incidence of antibody loss was calculated per 1000 person-years from primary immunization to the latest follow-up.

To calculate and to compare the anti-HBs persistence between the poor, the moderate, and the good responders, life-table analysis using the Kaplan-Meier method and log-rank tests were used which take censoring into account and are therefore the preferred analysis to compare time to antibody loss. In the analysis, we defined time to antibody loss as an event and presented it as an estimated means.

Incidence density ratios adjusted for the variables of interest (titer after primary immunization, gender, age group, and type of vaccine) were estimated using Cox's proportional hazards model to identify any factors associated with the loss of adequate anti-HBs titers. The analyses were carried out using the Statistical Package for the Social Sciences (IBM SPSS Statistics 26.0; SPSS Inc., Chicago, IL, USA).

\section{Results}

From November 1983 to May 1993, based on our campaign against HBV, 1329 HCWs started the immunization cycle, and 141 of them were excluded from our analysis because they did not complete the primary HBV vaccination cycle. Of the $1188 \mathrm{HCWs}$ that completed the immunization cycle, $307(26.8 \%)$ received a booster dose, and $340(38.6 \%)$ had a follow-up of fewer than 14 years, which left $541 \mathrm{HCWs}$ eligible for our analysis. Overall response after primary immunization was 96.9\% (539 HCWs). The flow-chart in Figure 1 summarizes the study group enrolment process.

Of the study population (539 subjects), $81.8 \%$ were female, and $59.4 \%$ were given the yeast-derived vaccine. Overall, the median age at the first vaccine dose against $\mathrm{HBV}$ was 21.0 years, the mean age was $21.6 \pm 4.8$ years, instead. According to gender, females were significantly younger than males, the mean ages were $21.1 \pm 4.6$ years and $23.8 \pm 5.3$ years, respectively $(p<0.001)$. Antibody titers after primary immunization identified $494(91.7 \%)$ as good responders, $37(6.9 \%)$ as moderate responders, and $8(1.5 \%)$ as poor responders (who tested negative during the follow-up). The probability of antibody loss was significantly lower for the moderate and good responders than for the poor responders. To be specific, the incidence of anti-HBs loss was 52.1 per 1000 person-years in poor responders (used as the reference group in the logistic regression analysis), 11.3 per 1000 person-years for the moderate responders (adj RR (95\% CI): $0.28(0.10-0.80), p=0.018)$, and 1.4 per 1000 person-years for the good responders (adj RR (95\% CI): $0.03(0.01-0.09), p<0.001$ ). No significant differences in the probability of antibody loss emerged in relation to gender ( $p=0.986)$ or age group $(p=0.556)$. Regarding the type of vaccine, there was a trend towards greater anti-HBs loss in HCWs given the yeast-derived vaccines than in those given the plasma-derived vaccines without reaching a statistically significant difference (adj RR (95\% CI): 2.1 (0.86-4.98), $p=0.107$ ) (Table 1). 


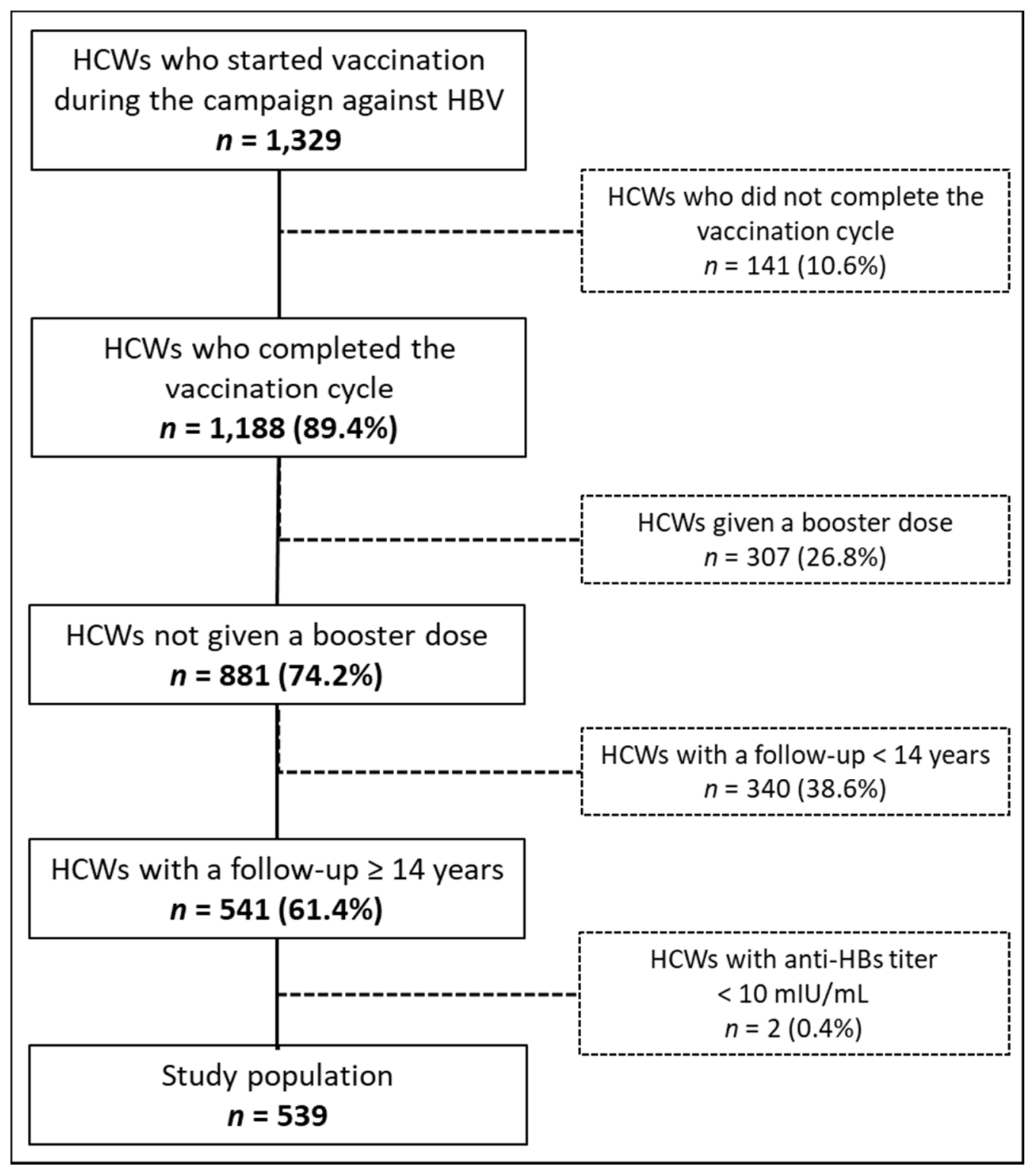

Figure 1. Flow diagram of the study group enrolment process.

The overall mean follow-up was $19.3 \pm 4.5$ years, with no significant differences between the groups of responders. The anti-HBs persistence up to 30 years after vaccination was $83.7 \%$ for good responders, and $56.8 \%$ for moderate responders, whereas anti-HBs persisted for up to 28 years in poor responders $(12.5 \%)$. The mean persistence of antiHBs differed significantly between the three groups, being: 19.2 years (95\% CI: 15.6-22.8), 25.4 years (95\% CI: 23.0-27.9), and 31.0 years (95\% CI: 30.5-31.5) for the poor, moderate, and good responders, respectively (Kaplan-Mayer log-rank test $p=0.001$ ) (Figure 2). 
Table 1. Antibody loss at follow-up in responders to primary immunization.

\begin{tabular}{|c|c|c|c|c|c|c|c|c|}
\hline \multirow[b]{2}{*}{ Characteristics } & \multicolumn{2}{|c|}{ HCWs } & \multicolumn{2}{|c|}{ Anti-HBs Negative } & \multirow[t]{2}{*}{ Person-Years } & \multicolumn{3}{|c|}{ Antibody Loss } \\
\hline & $N$ & $(\%)$ & $N$ & $(\%)$ & & $\begin{array}{c}\text { Incidence } \\
\text { Density/1000 } \\
\text { Person-Years }\end{array}$ & $\begin{array}{c}\text { Adjusted } \\
\text { RR (CI 95\%) }\end{array}$ & $p$ \\
\hline Overall & 539 & 100.0 & 29 & 5.4 & 10414.6 & 2.8 & & \\
\hline \multicolumn{9}{|l|}{$\begin{array}{l}\text { Titers after primary } \\
\text { immunization }\end{array}$} \\
\hline $10-99$ & 8 & 1.5 & 8 & 100.0 & 153.6 & 52.1 & - & - \\
\hline 100-999 & 37 & 6.9 & 8 & 21.6 & 707.6 & 11.3 & $\begin{array}{c}0.28 \\
(0.10-0.80)\end{array}$ & 0.018 \\
\hline$\geq 1000$ & 494 & 91.7 & 13 & 2.6 & 9553.3 & 1.4 & $\begin{array}{c}0.03 \\
(0.01-0.09)\end{array}$ & 0.000 \\
\hline \multicolumn{9}{|l|}{ Sex } \\
\hline Females & 441 & 81.8 & 22 & 5.0 & 8623.1 & 2.6 & $\begin{array}{c}1.0 \\
(0.40-2.50)\end{array}$ & 0.986 \\
\hline Male & 98 & 18.2 & 7 & 7.1 & 1791.5 & 3.9 & - & - \\
\hline \multicolumn{9}{|l|}{ Age group } \\
\hline$\leq 20$ & 267 & 49.5 & 9 & 3.4 & 5284.4 & 1.7 & - & - \\
\hline $21+$ & 272 & 50.5 & 20 & 7.4 & 5130.2 & 3.9 & $\begin{array}{c}1.3 \\
(0.50-3.20)\end{array}$ & 0.556 \\
\hline \multicolumn{9}{|l|}{ Type of vaccine } \\
\hline Plasma-derived & 219 & 40.6 & 8 & 3.7 & 4444.5 & 1.8 & - & - \\
\hline Yeast-derived & 320 & 59.4 & 21 & 6.6 & 5970.1 & 3.5 & $\begin{array}{c}2.1 \\
(0.86-4.98)\end{array}$ & 0.107 \\
\hline
\end{tabular}

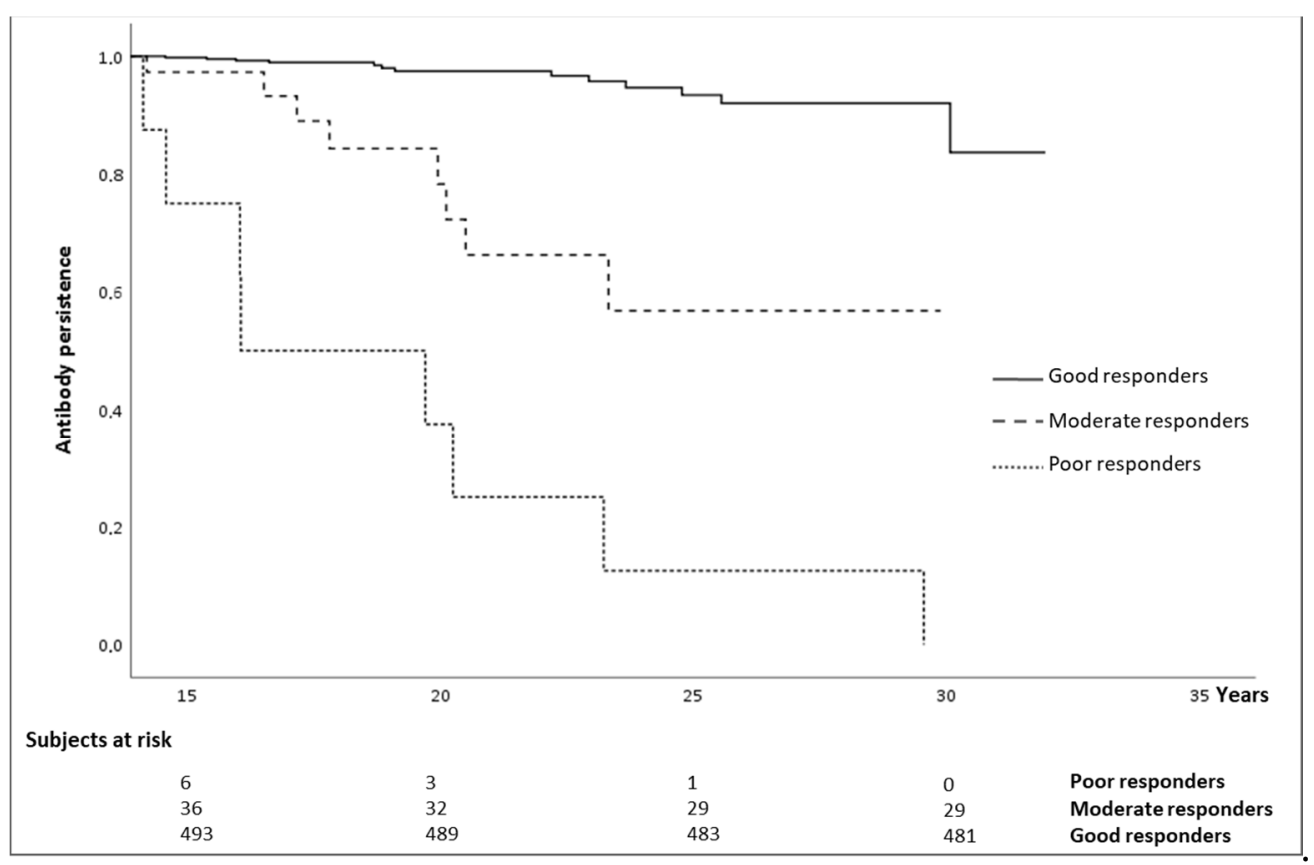

Figure 2. Anti-hepatitis B $(\mathrm{HB})$ persistence by anti-HBs titers after primary vaccination.

\section{Discussion}

To our knowledge, this is one of the few prospective studies to have been conducted on a selected group of healthy adults to assess the persistence of anti-HBs for up to 30 years after their primary immunization against $\mathrm{HBV}$, with no subsequent booster dose.

Our results indicate that response to the primary vaccination cycle was very high $(99.6 \%)$, in line with a response of $98.8 \%$ recorded by Floreani and colleagues [25]. We found that $91.7 \%$ of vaccinated HCWs had an anti-HBs titer higher than $1000 \mathrm{mIU} / \mathrm{mL}$. For $6.9 \%$ 
of them, it was between 100-999 mIU/mL. For 1.5\%, it was between 10-99 mIU/mL, and only 2 HCWs did not reach protective anti-HBs levels.

The persistence of anti-HBs during the follow-up correlated significantly with antiHBs titer after primary vaccination: for good responders, the likelihood of experiencing loss of anti-HBs was only $3 \%$ of the corresponding risk for poor responders.

In our previous study [25] on 422 subjects, protective levels of anti-HBs persisted 10 years after primary immunization in $>85 \%$ of cases, suggesting that a booster dose is unnecessary in healthy adults for 10 years. The present study shows that even 30 years after primary immunization, anti-HBs were still detectable in $84 \%$ of good responders and $56.8 \%$ of moderate responders, while $50 \%$ of poor responders had detectable anti-HBs 19 years after being immunized.

Other studies have also reported a significant relation between anti-HBs titer after primary vaccination and the persistence of anti-HBs over time. To be more specific, the findings of a retrospective cohort study conducted on HCWs from 2001 to 2012 showed that HCWs with higher initial anti-HBs titers after primary vaccination had significantly more persistent seropositivity. For short-term responders, a three-dose booster vaccination gave rise to a more durable anti-HBs positivity compared with a single-dose booster. For longterm responders, on the other hand, a single-dose booster sufficed to ensure a prolonged anti-HBs positivity [26]. Another study was performed to examine the persistence of immunity from 17 to 20 years after primary vaccination. This study involved more than 1300 healthy subjects. It found that, in the $25.5 \%$ of participants whose anti-HBs antibody titers were $<10 \mathrm{mIU} / \mathrm{mL}$, a challenge dose prompted a significant $93.1 \%$ increase in the number of individuals with an adequate anti-HBs positivity ( $\geq 10 \mathrm{mIU} / \mathrm{mL})$ [27].

These findings support current recommendations issued by the Advisory Committee on Immunization Practices (ACIP) and the European Consensus Group. According to these recommendations, HCWs who have been vaccinated against HBV and have a documented immunity (anti-HBs concentrations of $\geq 10 \mathrm{mIU} / \mathrm{mL}$ ) require no post-exposure prophylaxis, serological testing, or additional vaccination. This recommendation can be only valuable for "good" and "moderate" responders, however [14,24,28].

Recent studies reported an anamnestic response in more than $95 \%$ of subjects given a booster dose after revealing a non-protective anti-HBs titer $(<10 \mathrm{mIU} / \mathrm{mL})[29,30]$. This was confirmed by research conducted on about 10,000 students in the Veneto Region in 2019, which showed that anti-HB levels higher than 2 and lower than $10 \mathrm{mIU} / \mathrm{mL}$ were predictive of a prompt response to a booster [31]. In contrast, another recent study suggested the need for a booster dose 10 years after primary vaccination, for healthcare professionals at least [32].

As concerns the type of vaccine used, our results confirm that subjects given the yeast-derived vaccine are twice as likely as those given the plasma-derived vaccine to have declining antibody levels [25], although this difference was not statistically significant in our sample. In a previous study of ours, individuals who were initially given plasma-derived vaccines were better seroprotected than those given yeast-derived vaccines. The former had significantly higher anti-HBs geometric mean titers (GMTs) during their follow-up, despite both groups reaching similar GMTs after primary immunization [25]. Studies on antibody kinetics have shown that, after an initial drop in titer during the first few months, the decline in antibody concentrations becomes much slower in subsequent years [33]. This gradual decline in anti-HBs titer also depends on the titer reached after the primary vaccination cycle [34]. Findings emerging from studies on infants have painted the same picture [35]. That said, there is no medical evidence to suggest that vaccinated healthy individuals lose their immunity simply because their anti-HBs levels drop below $10 \mathrm{mIU} / \mathrm{mL}$. The GMT is only one of the variables to consider when judging an individual's protection. Cellular immunity has a more important role in the anamnestic response, and the virus's incubation period is longer than the time it takes to mount an anamnestic response. Finally, vaccination screening in HCWs is also useful to identify infected subjects with active HBV infection in order to reduce the transmission risk to patients. Indeed, according to the 
2017 Clinical Practice Guidelines of the European Association for the Study of the Liver, HCWs performing exposure-prone procedures with serum HBV DNA $>200 \mathrm{IU} / \mathrm{mL}$ may be treated with nucleos(t)ide analog [36].

The available evidence toward an effect of male gender on antibody loss is not robust: our findings are not able to suggest a role of the gender in the antibody loss at follow-up. While our findings are in line with most of the past literature, a study conducted by Wood and colleagues [37] showed a significant association between male gender and antibody loss, but this was significant only regarding Engerix-B recipients and not for Recombivax HB recipients. However, a more recent study by Yang and colleagues [38] showed an association between male gender and vaccine non-response. As suggested by the authors, part of the heterogeneity in the vaccine response may reside in the opposite effects of sex hormones on the epigenetic adjustment of genetic expression and in the gene structure on the $\mathrm{X}$ chromosome differing between $\mathrm{XX}$ females and $\mathrm{XY}$ male, but further research is needed in this specific field.

The main weakness of our study lies in the lack of data relating to HCWs' specific features and behavior (alcohol consumption, smoking habits, obesity, sexual behavior, and so on), which are variables believed to affect the persistence of protective anti-HBs antibodies over time [39,40]. Another limitation of the study concerns the number of poor responders, but this is due to the generally good response to primary immunization. In addition, all participants involved in our study did not report any previous contact with the HBV prior to primary immunization and received a full course of anti-HBV vaccination as HCWs for the first time in their life at the time of recruitment (or starting of the internship) by their healthcare facility, in fact, the mean age of the studied population was of 20.0 years. This may pose some limitations to the extensibility of results to either the following cohorts of HCWs or the general population: in 1991 in Italy, indeed, a universal routine anti-HBV vaccination program was implemented, including both infants in the first year of age- -with a schedule at three, five and eleven months, while vaccination at birth was recommended for only infants born to HBsAg positive mothers-and a catch-up strategy addressed to adolescents at the age of 12 for the first 12 years of application in order to cover, in only a dozen years, the whole Italian population aged 0-24 years. As shown by recent studies conducted by Chiara and Coppola, the rate of antibody loss correlates inversely with vaccination age while the level of antibody titer is directly related to the age of primary immunization [5,41].

On the other hand, our study can rely on a quite large cohort of more than 500 participants and, most of all, a considerably long follow-up time up to 30 years.

\section{Conclusions}

The present study demonstrated a good persistence of protective anti-HBs titers in HCWs at occupational risk of HBV for up to 30 years (even without a booster dose) if their starting titer after the primary vaccination cycle was greater than $100 \mathrm{mIU} / \mathrm{mL}$. This result supports current guidelines, which do not recommend a booster dose for HCWs whose antibody titer after primary immunization was $\geq 10 \mathrm{mIU} / \mathrm{mL}$.

Author Contributions: Conceptualization, A.F., S.C., M.L.S. and V.B.; data curation, M.L.S., P.M. and A.V.; formal analysis, S.C. and P.F. investigation, M.L.S. and V.B.; methodology, S.C., P.F., and V.B. supervision, S.C., A.T. and V.B.; validation, A.T., M.L.S., and V.B.; writing-original draft, A.F., S.C. and V.B.; writing-review and editing, S.C., P.F., M.F. and V.B. All authors have read and approved the version of the manuscript submitted for publication.

Funding: This research received no external funding.

Institutional Review Board Statement: According to Italian national guidelines (DM 18/03/1998), anonymized data may be analyzed and used in aggregate form for scientific studies without further authorization, meaning that no formal ethical committee approval was needed for the present study. This study complies with the requirements of the latest version of the Declaration of Helsinki. 
Informed Consent Statement: The need for patients' consent was waived because of the anonymous nature of the data and the fact that its recording is mandatory. The data were treated with full respect for confidentiality, in accordance with Italian legislation. Before the database was made available to the authors, all sensitive data concerning the patients considered in the study were replaced with anonymous codes, making it impossible to identify the individuals concerned.

Data Availability Statement: All relevant data are within the paper. Requests for additional information should be addressed to the corresponding author and data may be provided on reasonable request.

Conflicts of Interest: V.B. has received grants and nonfinancial support from Seqirus, GSK, Novartis, Pfizer, Merck Italy, and Sanofi Pasteur, for purposes unrelated to the present study. The other authors have no potential conflicts of interest to disclose.

\section{References}

1. World Health Organization Geneva, Switzerland. Global Hepatitis Report for 2017. Available online: https:/ /www.who.int/ hepatitis/publications/global-hepatitis-report2017/en/ (accessed on 11 November 2020).

2. Nicolini, L.A.; Orsi, A.; Tatarelli, P.; Viscoli, C.; Icardi, G.; Sticchi, L. A Global View to HBV Chronic Infection: Evolving Strategies for Diagnosis, Treatment and Prevention in Immunocompetent Individuals. Int. J. Environ. Res. Public Health 2019, $16,3307$. [CrossRef]

3. Trépo, C.; Chan, H.L.Y.; Lok, A. Hepatitis B Virus Infection. Lancet 2014, 384, 2053-2063. [CrossRef]

4. Datta, S.; Chatterjee, S.; Veer, V.; Chakravarty, R. Molecular Biology of the Hepatitis B Virus for Clinicians. J. Clin. Exp. Hepatol. 2012, 2, 353-365. [CrossRef] [PubMed]

5. Coppola, N.; Corvino, A.R.; De Pascalis, S.; Signoriello, G.; Di Fiore, E.; Nienhaus, A.; Sagnelli, E.; Lamberti, M. The Long-Term Immunogenicity of Recombinant Hepatitis B Virus (HBV) Vaccine: Contribution of Universal HBV Vaccination in Italy. BMC Infect. Dis 2015, 15, 149. [CrossRef]

6. European Centre for Disease Surveillance and Control. Hepatitis B. Annual Epidemiological Report for 2017. Available online: https:/ / www.ecdc.europa.eu/sites/default/files/documents/hepatitis-B-annual-epidemiological-report-2017.pdf (accessed on 15 November 2020).

7. De Schryver, A.; Claesen, B.; Meheus, A.; van Sprundel, M.; Francois, G. European Survey of Hepatitis B Vaccination Policies for Healthcare Workers. Eur. J. Public Health 2011, 21, 338-343. [CrossRef]

8. Elseviers, M.M.; Arias-Guillén, M.; Gorke, A.; Arens, H.-J. Sharps injuries amongst healthcare workers: Review of incidence, transmissions and costs: Sharps injuries amongst healthcare workers. J. Ren. Care 2014, 40, 150-156. [CrossRef] [PubMed]

9. Garzillo, E.M.; Arnese, A.; Coppola, N.; Corvino, A.; Feola, D.; Monaco, M.G.L.; Signoriello, G.; Marsella, L.T.; Arena, P.; Lamberti, M. HBV Vaccination Status among Healthcare Workers: A Cross-Sectional Study. J. Infect. Prev. 2020, 21, 23-27. [CrossRef] [PubMed]

10. Burnett, R.J.; Francois, G.; Mphahlele, M.J.; Mureithi, J.G.; Africa, P.N.; Satekge, M.M.; Mokonoto, D.M.; Meheus, A.; van Sprundel, M. Hepatitis B vaccination coverage in healthcare workers in Gauten province, South Africa. Vaccine 2011, 29, 4293-4297. [CrossRef]

11. Tufon, K.A.; Meriki, H.D.; Kwenti, T.E.; Tony, N.J.; Malika, E.; Bolimo, A.F.; Kouanou, Y.S.; Nkuo-Akenji, T.; Anong, D.N. HBV Transmission Risk Assessment in Healthcare Workers, Household and Sexual Contacts of HBV Infected Patients in the Southwest Region of Cameroon. Oman Med. J. 2019, 34, 313-321. [CrossRef]

12. CDC. Hepatitis B FAQs for the Public. Available online: https://www.cdc.gov/hepatitis/hbv/bfaq.htm (accessed on 28 November 2020).

13. Yu, A.S.; Cheung, R.C.; Keeffe, E.B. Hepatitis B Vaccines. Infect. Dis. Clin. N. Am. 2006, 20, 27-45. [CrossRef] [PubMed]

14. Advisory Committee on Immunization Practices; Centers for Disease Control and Prevention (CDC) Immunization of Health-Care Personnel. Recommendations of the Advisory Committee on Immunization Practices (ACIP). Mmwr Recomm Rep. 2011, 60, 1-45.

15. Bruce, M.G.; Bruden, D.; Hurlburt, D.; Zanis, C.; Thompson, G.; Rea, L.; Toomey, M.; Townshend-Bulson, L.; Rudolph, K.; Bulkow, L.; et al. Antibody Levels and Protection After Hepatitis B Vaccine: Results of a 30-Year Follow-up Study and Response to a Booster Dose. J. Infect. Dis. 2016, 214, 16-22. [CrossRef]

16. Immunization Action Coalition (IAC). Hepatitis B. Available online: https://www.immunize.org/askexperts/experts_hepb.asp (accessed on 30 November 2020).

17. Middleman, A.B.; Baker, C.J.; Kozinetz, C.A.; Kamili, S.; Nguyen, C.; Hu, D.J.; Spradling, P.R. Duration of Protection After Infant Hepatitis B Vaccination Series. PEDIATRICS 2014, 133, e1500-e1507. [CrossRef] [PubMed]

18. Khafagy, A.; AlJahdaly, I.; Goweda, R. Hepatitis B Vaccine: Assessment of Immunologic Response, Coverage Rate, and Factors Influencing Seroreactivity. Clin. Lab. 2020, 66. [CrossRef] [PubMed]

19. Averhoff, F.; Mahoney, F.; Coleman, P.; Schatz, G.; Hurwitz, E.; Margolis, H. Immunogenicity of Hepatitis B Vaccines. Am. J. Prev. Med. 1998, 15, 1-8. [CrossRef]

20. Weber, D.J.; Rutala, W.A.; Samsa, G.P.; Santimaw, J.E.; Lemon, S.M. Obesity as a Predictor of Poor Antibody Response to Hepatitis B Plasma Vaccine. JAMA 1985, 254, 3187-3189. [CrossRef] [PubMed] 
21. Liu, F.; Guo, Z.; Dong, C. Influences of Obesity on the Immunogenicity of Hepatitis B Vaccine. Hum. Vaccines Immunother. 2017, 13, 1014-1017. [CrossRef]

22. Mast, E.E.; Weinbaum, C.M.; Fiore, A.E.; Alter, M.J.; Bell, B.P.; Finelli, L.; Rodewald, L.E.; Douglas, J.M.; Janssen, R.S.; Ward, J.W.; et al. A Comprehensive Immunization Strategy to Eliminate Transmission of Hepatitis B Virus Infection in the United States: Recommendations of the Advisory Committee on Immunization Practices (ACIP) Part II: Immunization of Adults. Mmwr. Recomm. Rep. 2006, 55, 1-33.

23. Lamberti, M.; De Rosa, A.; Garzillo, E.M.; Corvino, A.R.; Sannolo, N.; De Pascalis, S.; Di Fiore, E.; Westermann, C.; Arnese, A.; Gabriella, D.G.; et al. Vaccination against Hepatitis b Virus: Are Italian Medical Students Sufficiently Protected after the Public Vaccination Programme? J. Occup. Med. Toxicol. 2015, 10. [CrossRef] [PubMed]

24. European Consensus Group on Hepatitis B Immunity. Are Booster Immunisations Needed for Lifelong Hepatitis B Immunity? Lancet 2000, 355, 561-565. [CrossRef]

25. Floreani, A.; Baldo, V.; Cristofoletti, M.; Renzulli, G.; Valeri, A.; Zanetti, C.; Trivello, R. Long-Term Persistence of Anti-HBs after Vaccination against HBV: An 18 Year Experience in Health Care Workers. Vaccine 2004, 22, 607-610. [CrossRef]

26. Yoshioka, N.; Deguchi, M.; Hagiya, H.; Kagita, M.; Tsukamoto, H.; Takao, M.; Yoshida, H.; Yamamoto, N.; Akeda, Y.; Nabetani, Y.; et al. Durability of Immunity by Hepatitis B Vaccine in Japanese Health Care Workers Depends on Primary Response Titers and Durations. PLoS ONE 2017, 12, e0187661. [CrossRef]

27. Zhao, Y.-L.; Han, B.-H.; Zhang, X.-J.; Pan, L.-L.; Zhou, H.-S.; Gao, Z.; Hao, Z.-Y.; Wu, Z.-W.; Ma, T.-L.; Wang, F.; et al. Immune Persistence 17 to 20 Years after Primary Vaccination with Recombination Hepatitis B Vaccine (CHO) and the Effect of Booster Dose Vaccination. BMC Infect. Diseases 2019, 19, 1-7. [CrossRef] [PubMed]

28. Gara, N.; Abdalla, A.; Rivera, E.; Zhao, X.; Werner, J.M.; Liang, T.J.; Hoofnagle, J.H.; Rehermann, B.; Ghany, M.G. Durability of Antibody Response Against Hepatitis B Virus in Healthcare Workers Vaccinated as Adults. Clin. Infect. Dis. 2015, 60, 505-513. [CrossRef]

29. Chiara, F.; Bartolucci, G.B.; Cattai, M.; Piazza, A.; Nicolli, A.; Buja, A.; Trevisan, A. Hepatitis B Vaccination of Adolescents: Significance of Non-Protective Antibodies. Vaccine 2013, 32, 62-68. [CrossRef]

30. Dini, G.; Toletone, A.; Barberis, I.; Debarbieri, N.; Massa, E.; Paganino, C.; Bersi, F.; Montecucco, A.; Alicino, C.; Durando, P. Persistence of Protective Anti-HBs Antibody Levels and Anamnestic Response to HBV Booster Vaccination: A Cross-Sectional Study among Healthcare Students 20 Years Following the Universal Immunization Campaign in Italy. Hum. Vaccines Immunother. 2017, 13, 440-444. [CrossRef]

31. Trevisan, A.; Frasson, C.; De Nuzzo, D.; Nicolli, A.; Scapellato, M.L. Significance of Anti-HB Levels below 10 IU/L after Vaccination against Hepatitis B in Infancy or Adolescence: An Update in Relation to Sex. Hum. Vaccin Immunother. 2020, 16, 460-464. [CrossRef]

32. Sahana, H.V.; Sarala, N.; Prasad, S.R. Decrease in Anti-HBs Antibodies over Time in Medical Students and Healthcare Workers after Hepatitis B Vaccination. Biomed. Res. Int. 2017, 2017, 1-5. [CrossRef]

33. Jilg, W.; Schmidt, M.; Deinhardt, F. Persistence of Specific Antibodies after Hepatitis B Vaccination. J. Hepatol. 1988, 6, 201-207. [CrossRef]

34. Trivello, R.; Chiaramonte, M.; Ngatchu, T.; Baldo, V.; Majori, S.; Moschen, M.E.; Simoncello, I.; Renzulli, G.; Naccarato, R. Persistence of Anti-HBs Antibodies in Health Care Personnel Vaccinated with Plasma-Derived Hepatitis B Vaccine and Response to Recombinant DNA HB Booster Vaccine. Vaccine 1995, 13, 139-141. [CrossRef]

35. Wu, J.S.; Hwang, L.Y.; Goodman, K.J.; Beasley, R.P. Hepatitis B Vaccination in High-Risk Infants: 10-Year Follow-Up. J. Infect. Dis 1999, 179, 1319-1325. [CrossRef]

36. EASL 2017 Clinical Practice Guidelines on the management of hepatitis B virus infection. J. Hepatol. 2017, 67, 370-398. [CrossRef] [PubMed]

37. Wood, R.C.; MacDonald, K.L.; White, K.E.; Hedberg, C.W.; Hanson, M.; Osterholm, M.T. Risk Factors for Lack of Detectable Antibody Following Hepatitis B Vaccination of Minnesota Health Care Workers. JAMA 1993, 270, 2935-2939. [CrossRef] [PubMed]

38. Yang, S.; Tian, G.; Cui, Y.; Ding, C.; Deng, M.; Yu, C.; Xu, K.; Ren, J.; Yao, J.; Li, Y.; et al. Factors Influencing Immunologic Response to Hepatitis B Vaccine in Adults. Sci. Rep. 2016, 6. [CrossRef] [PubMed]

39. Tripathy, S.; Sathi, H.C.; Puspa Saha, S.; Shankar, R.; Singh, V.K. Study of immune response after hepatitis B vaccination in medical students and healthcare workers. Indian J. Prev. Soc. Med. 2011, 42, 315-321.

40. Nashibi, R.; Alavi, S.M.; Yousefi, F.; Salmanzadeh, S.; Moogahi, S.; Ahmadi, F.; Farashahinejad, M. Post-Vaccination Immunity Against Hepatitis B Virus and Predictors for Non-Responders Among Medical Staff. Jundishapur J. Microbiol. 2015, 8. [CrossRef]

41. Chiara, F.; Bartolucci, G.B.; Mongillo, M.; Ferretto, L.; Nicolli, A.; Trevisan, A. Hepatitis B Vaccination at Three Months of age: A Successful Strategy? Vaccine 2013, 31, 1696-1700. [CrossRef] 